\title{
Primary Nodular Hepatic Tuberculosis Mimicking Hepatic Neoplasia in an Immunocompetent Host
}

\author{
Levindo Tadeu Ferreira Figueiredo Dias¹, Gisane Cavalcanti Rodrigues², Diogo Santos Barbosa², Domício Carvalho Lacerda ${ }^{2}$ and \\ Marcelo Freire Ruas ${ }^{2}$ \\ ${ }^{1}$ Service of Oncology of São Lucas de Montes Claros Hospital, State University of Montes Claros (UNIMONTES); ${ }^{2}$ Clemente de Faria \\ Universitary Hospital (HUCF); Montes Claros, MG, Brazil
}

\begin{abstract}
We present and describe a case of nodular primary hepatic tuberculosis mimicking hepatic neoplasia in an immunocompetent host. This particularly rare presentation, associated with unspecific imaging, laboratory and clinical findings and relatively unspecific microbiological results make diagnosis extremely difficult, usually requiring surgical intervention.
\end{abstract}

Key-Words: Tuberculosis, hepatic tuberculosis, differential diagnosis

Tuberculosis is an increasing problem throughout the world; consequently, it is vital to recognize the uncommon presentations of this disease. Among the 22 countries where most of tuberculosis cases occur, Brazil is $15^{\text {th }}$ in the ranking [1]. Hepatic tuberculosis (HTB) is quite rare, with less than 100 cases in the medical literature [2]. Reports of HTB in the absence of miliary abdominal tuberculosis are restricted to a few cases $[3,4]$. Common problems of the liver, such as abscesses and tumors, can be stimulated by HTB [5,6]. We can include HTB as a disease that presents with fever of unknown origin $[7,8]$. HTB generally occurs due to the reactivation of an old focus of tuberculosis, or on rare occasions as a result of a primary hepatic case [9]. The clinical presentation is generally atypical, as are the laboratory and radiological exams. Intra-abdominal tuberculosis has a high death rate and a difficult diagnosis, frequently made with laparotomy. The objective of this report is to describe an extremely rare presentation of tuberculosis, which should contribute to our knowledge towards differential diagnosis hepatic tumors.

\section{Case Report}

A female patient, a white 56 year-old housewife, was conducted to the oncology service to be tested for clinical evidence of neoplasm. The patient related a story of two months of hyporexia, fever and a loss of weight of 10 kilograms. She denied a previous tuberculosis history or exposure to the bacillus. She denied use of regular medication or previous pathologies. Laboratory exams showed: blood count with normocytic and normochromic anemia (HGB: 10.2g\%; VCM: 88fl; HCM: 29pg), normal leucogram and blood platelets; transaminases, gamma glutamyl transpeptidase, proteins and kidney functions were considered normal. Alkaline phosphatase was 280U/L (50250). ELISAs (enzyme-linked immunoabsorbent assay) for

Received on 9 September 2008; revised 11 January 2009.

Address for correspondence: Dr. Domício Carvalho Lacerda. Av.: Cula Mangabeira, 562, Bairro Santo Expedito. CEP:39.401-002. Montes Claros/MG. Telefax: (38) 3229-8520. E-mail: domiciolacerda@hotmail.com.

The Brazilian Journal of Infectious Diseases 2009;13(1):153-154. (C) 2009 by The Brazilian Journal of Infectious Diseases and Contexto Publishing. All rights reserved.
HIV 1 and 2 were negative. Tumor protein tests, including alpha-fetoprotein, were negative. The thorax radiological exam was within the normal limits. An upper digestive tract endoscopy was necessary to exclude gastric neoplasm; it showed esophagitis of light intensity. Ultrasonography exams showed four hypoechoic, solid hepatic nodule lesions; the biggest one was on the left lobe, measuring $4.8 \times 3 \mathrm{~cm}$. Tomography exams of the abdomen showed a few attenuation lesions (Figure 1). A diagnostic laparoscopy was made, with biopsy of the lesions. Investigation for resistant acid-fast bacilli in the biopsy material was negative. The histopathological study revealed a chronic granulomatous inflammation with caseous necrosis, compatible with tuberculosis, with no signal of malignity. The results were confirmed immunohistochemically. Although the pathological agent was not visualized, based on the clinical manifestations plus the histopathological findings, we began treatment with antitubercular drugs (Rifampin, Isoniazid and Pyranizamid). The patient had a progressive clinical improvement. After the end of therapy, the image exams were repeated, showing complete resolution of the case (Figure 2).

\section{Discussion}

HTB has been classified by Levine as miliary tuberculosis, pulmonary tuberculosis with hepatic compromise, primary hepatic tuberculosis, focal or abscess tuberculosis and tuberculous cholangitis [10]. The most common form is miliary tuberculosis, in which hematogenous spread occurs through the hepatic artery [2]. Tuberculosis that only involves the liver is considered to be rare due to the low tension of hepatic oxygen, being an unfavorable site for the growth of mycobacteria [11].

The most common clinical findings are abdominal pain, fever and weight loss. Hepatomegaly is frequently found. The laboratory investigation frequently shows an increase in alkaline phosphatase, with normal transaminases [2,12,13]. Less specific findings include anemia, hypoalbuminemia and hyponatremia [2]. In most patients, increased VHS and hypergammaglobulinaemia is found $(76.5 \%$ and $76.9 \%$ of the patients, respectively) [13]. Our patient had only slightly high alkaline phosphatase and anemia typical of chronic disease (normocytic and normochromic), consistent with the medical literature. Image studies, are frequently a diagnostic challenge, 
Figure 1. Tomography exams of the abdomen showed a few attenuation lesions.

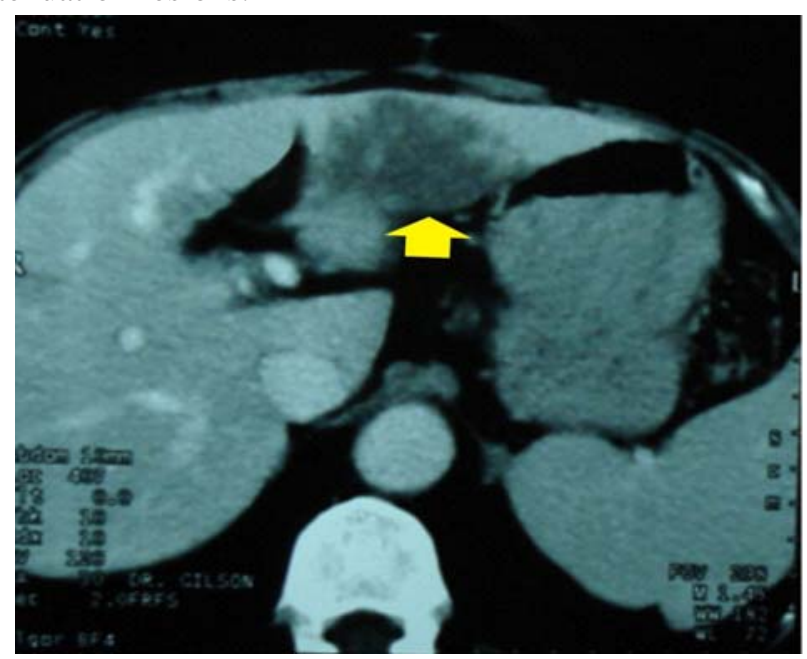

with many potential and differential diagnoses, including primary hepatocellular carcinoma [14]. Tomography shows a hypodense mass, with or without contrast capitation and heterogenic densities with a necrotic center and calcification in a "bull's eye". Ultrasonography can show hypoechoeic nodes and, rarely, hyperechoeic nodules. Most lesions of hepatic tuberculosis are small [12]. Giant lesions, larger than $3 \mathrm{~cm}$ in diameter, are rare [15]. Due to the polymorphism of the lesions on imaging, often similar to primary neoplasms or metastasis, diagnosis is difficult with a histopathological exam [12]. For this reason, biopsy surgeries are often required [16]. Thus, as described in the literature, given the tumoral aspect of the hepatic lesion in our case, the propaedeutic indicated a probable hepatic cancer. Microscopy can reveal classic caseous granulomas, epithelial granuloma and non-caseous or caseous necrosis.

Unspecific findings for this condition include Kupffer hyperplasia cells, focal hepatocytic necrosis with infiltration of cells, and portal inflammation [12]. The bacilli can be easily found in caseous necrosis, but their absence cannot exclude the diagnosis [17]. The positive rate of exams for bacilli varies from 0 to $45 \%$ and the culture results vary from $10 \%$ to $60 \%$ (10). PCR (Polymerase Chain Reaction) is a useful tool in tuberculosis diagnosis, with a positivity rate of 57\% [18]. However, we still cannot use this tool in most public services. So, even without finding the tuberculosis bacillus, but in the face of a compatible histopathological exam, a diagnosis of hepatic tuberculosis was made. In Brazil, the recommended treatment is with Isoniazid, Rifampin and Pyrazinamide.

In summary, isolated hepatic tuberculosis, although uncommon, should be included as one of the differential liver mass diagnoses in areas endemic for tuberculosis, especially when the patient presents upper abdominal pain, fever and hepatomegaly. The best method of diagnosis is still hepatic biopsy. Caseous granuloma findings are frequently considered as a diagnosis criterion.
Figure 2. Tomography exams of the abdomen showed complete resolution of the case.

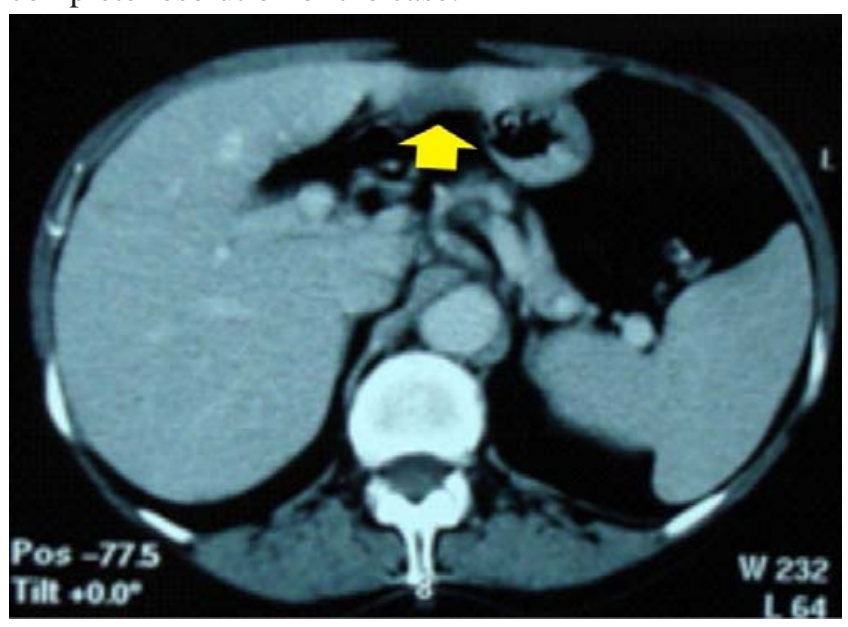

References

1. Hijar M.A., Procópio M.J., Freitas L.M.R., AJ et al. Epidemiologia da tuberculose. Pulmão RJ 2005;14(4):310-4.

2. Brookes M.J., Field M., Dawkins D.M., et al. Massive primary hepatic tuberculoma mimicking hepatocelular carcinoma in an immunocompetent. MedGenMed 2006;8(3):11.

3. Rhaman Q.M., Nath N.C., Midya S. Hepatic tuberculosis - a case report. J Indian Med Assoc 2002;100:522-3.

4. Rahmatulla R.H., Al-Mofleh I.A., Al-Rashed R.S., et al. Tuberculous liver abscess: a case report and review of literature. Eur J Gastroenterol Hepatol 2001;13:437-40.

5. Agrawal C.S., Jain B.K., Das D.N., Singh N.P. Solitary tuberculous abscess of liver. J Indian Med Assoc 2001;99:591-2.

6. Sheen-Chen S.M., Chen M.C., Hu T.H., et al. Computed tomography and angiography in hepatic tuberculosis mimicking liver tumor. Int J Tuberc Lung Dis 2001;5;876-8.

7. Loja O.D., Vilca V.M., Alvarez B.P. Granulomatous tuberculous hepatitis as cause of fever of unknown origin. Rev Gastroenterol 2002;22:324-9.

8. Lee D.G., Choi J.H., Kim Y.J., et al. Hepatosplenic tuberculosis mimicking disseminated candidiasis in patients with acute leukemia. Int J Hematol 2001;73:119-21.

9. Mert A., Ozaras R., Tabak F., et al. Localized hepatic tuberculosis. Eur J of Internal Medicine 2003;14:511-2.

10. Levine C. Primary macronodular hepatic tuberculosis: US and CT appearances. Gastrointest Radiol 1990;15:307-9.

11. Chien R.N., Lin P.Y., Liaw Y.F. Hepatic tuberculosis: comparison of miliariy and local form. Infection 1995;23:5-8.

12. Huang W.T., Wang C.C., Chen W.J., et al. The nodular form of hepatic tuberculosis: a review with five additional new cases. J Clin Pathol 2003;56(11):835-83.

13. Sheen-Chen S.M., Chen M.C., Hu T.H., et al. Computed tomography and angiography in hepatic tuberculosis mimicking liver tumor. Int J Tuberc Lung Dis 2001;5(9):876-8.

14. Chan H.S., Pang J. Isolated giant tuberculomata of the liver detected by computed tomography. Gastrointest Radiol 1989;14:305-7.

15. Bernhard J.S., Bhatia G., Knauer C.M. Gastointestinal tuberculosis: an eighteen-patient experience and review. J Clin Gastroenterol 2000;30:397-402.

16. Varela M., Fernández J., Navasa M., Bruix J. Pseudotumoral hepatic tuberculosis. J Hepatol 2003;39(4):654.

17. McCluggage W.G., Slaan J.M. Hepatic granulomas in Northern Ireland: a thirteen year review. Histopathology 1994;25:219-28.

18. Diaz M.L., Herrera T., Vidal Y.L., et al. Polymerase chain reaction for the detection of Mycobacterium tuberculosis DNA in tissue and assesment of its utility in the diagnosis of the hepatic granulomas. J Lab Clin Med 1996;127:359-63. 